\title{
Interação, Aprendizado Tecnológico e Inovativo no Pólo de TIC da Região de Campinas: uma caracterização com ênfase nas atividades tecnológicas desenvolvidas pelas empresas beneficiárias da Lei de Informática*
}

\author{
Antonio Carlos Diegues \\ Economista - UNICAMP; Mestrando em Economia - IE/UNICAMP \\ José Eduardo Roselino \\ Economista - UNESP; Mestre e Doutor em Economia - IE/UNICAMP; \\ Professor do Centro Universitário Salesiano de São Paulo - UNISAL
}

Recebido: 13/3/2006 Aprovado: 15/9/2006

\section{RESUMO}

Este artigo busca caracterizar as atividades tecnológicas desenvolvidas no pólo de tecnologias de informação e comunicação (TIC) da região de Campinas, identificando as interaçôes entre agentes e instituições locais. $\mathrm{O}$ artigo analisa o desenvolvimento tecnológico do pólo em dois períodos: ao longo da década de 1980 até meados dos anos 1990, e no período pós-privatização. Assim pode-se analisar as transformaçōes que o aprendizado tecnológico e inovativo local sofreram devido à desestruturação do Sistema Telebrás e à consolidação de um novo arcabouço institucional (Lei de Informática). Tal análise permite afirmar que essas transformações não significaram o fim dos esforços tecnológicos formais. Os investimentos em atividades tecnológicas e inovativas efetuados

\footnotetext{
* Os autores agradecem o apoio da FAPESP, bem como o convênio FINEP/GEEIN para a realização do projeto DPP (Diretório de Pesquisa Privada). Agradecem também aos pareceristas anônimos pelas observações e sugestões que muito
} contribuíram para o aprimoramento deste trabalho. 
nas empresas e nas instituições de pesquisa da região foram mantidos, ainda que mediante transformaçóes. Essa constatação mostra que as atividades de importantes laboratórios, departamentos de P\&D ou institutos de pesquisa vinculados às empresas de TIC locais são, em grande medida, resultado da existência de um arcabouço institucional de fomento.

PalaVRas-Chave | Tecnologias de Informação e Comunicação; Política Industrial, Científica e Tecnológica; Economia do Conhecimento; Pólos de Atividades de TIC

CÓdigos JEL | O31; O38; L63; R11

\section{ABSTRACT}

This paper aims at describing the technological activities developed in Campinas information and communication technologies (ICT) cluster and at identifying the local interactions between agents and institutions. The paper analyzes the cluster technological development in two periods: from the 1980s to the mid-1990s, and in the period after privatization. It analyzes the transformations in the collective learning process and in the creation of local innovative capabilities after the privatization of the Telebrás System and the consolidation of a new institutional framework (Informatics Law). Such analysis shows that these transformations did not imply the end of formal technological efforts. The firms' and research institutions' investments in technological and innovative activities of the cluster have been maintained, although undergoing transformations. This fact shows that the activities of important laboratories, R\&D departments or research institutes related to local ICT firms are due, to a great extent, to the existence of an institutional support framework.

KEYWORDS | Information and Comunication Technologies; Industrial and Technological Policy; Knowledge Economy; TIC Clusters

JEL-CODES $\quad$ O31; O38; L63; R11 


\section{Introdução}

O objetivo central deste trabalho é avançar na avaliação dos esforços tecnológicos e inovativos desenvolvidos no pólo de TIC da região de Campinas. Para tanto, procura-se destacar os efeitos oriundos das transformações do ambiente institucional e concorrencial no período pós-privatização.

Caracterizando-se como o segundo maior centro de desenvolvimento econômico do estado de São Paulo, a região de Campinas ${ }^{1}$ apresenta uma grande concentração de empresas de Tecnologia da Informação e Comunicação.

As origens históricas da atual configuração produtiva local estão relacionadas à implantação e às trajetórias das grandes empresas do setor que se instalaram pioneiramente nessa região, bem como o papel determinante de universidades e instituiçóes públicas de pesquisa, especialmente durante as décadas de 1970 e 1980.

Com as grandes transformações do marco regulatório e do ambiente competitivo ocorridas desde meados dos anos 1990, mediante a acelerada abertura comercial e as privatizações no setor, este pólo passou por um importante reordenamento. Essa nova configuração trouxe um peso maior do capital estrangeiro com o ingresso ou expansão das operaçôes de empresas multinacionais na região. Nesse mesmo movimento, a maioria das empresas de capital nacional que orbitavam em torno do CPqD - Centro de Pesquisa e Desenvolvimento da Telebrás, compunham a estrutura produtiva do "Sistema Telebrás" encerraram suas atividades ou foram incorporadas pelos grupos estrangeiros.

O próprio $\mathrm{CPqD}$, bem como as raras empresas nacionais que sobreviveram a essas transformações passaram por profundos processos de reestruturação, redefinindo seus focos de atuação. $\mathrm{O} \mathrm{CPqD}$ passou à condição de fundação de caráter privado (ainda que parcialmente mantido com recursos de origem "paraestatal") com uma atuação voltada ao mercado.

Todas essas transformações não significaram, no entanto, o fim dos esforços tecnológicos formais. Os investimentos em atividades tecnológicas e inovativas efetuados nas empresas da região, bem como nas instituições de pesquisa preservaram-se, ainda que mediante reestruturaçôes.

\footnotetext{
O termo região de Campinas aqui utilizado corresponde, segundo o IBGE, à microrregião de Campinas e compreende 16 municípios. Dentre estes, destacam-se pela presença de importantes empresas de TIC - objeto de estudo no presente trabalho - os municípios de Campinas, Indaiatuba e Jaguariúna.
} 
A existência de importantes laboratórios e departamentos de P\&D ou institutos de pesquisa vinculados às empresas locais é resultado, em grande medida, da existência de um arcabouço institucional de fomento.

Os elementos apontados neste trabalho fundamentam-se em uma pesquisa de campo realizada junto aos responsáveis pelas atividades tecnológicas (gerente de P\&D ou função análoga) de empresas e instituições selecionadas (seção 5). As entrevistas junto às empresas foram pautadas pela aplicação de um questionário voltado à identificação e qualificação dos esforços inovativos desenvolvidos internamente e em parceria com outras empresas e institutos de pesquisa. Já as entrevistas realizadas junto às instituições (SOFTEX e CPqD) basearam-se em um roteiro de questões voltadas à identificação do papel destas na articulação com os demais agentes locais.

$\mathrm{Na}$ pesquisa de campo, ganhou destaque a vigência da Lei de Informática (nas suas distintas e sucessivas versões), como condição determinante e necessária para a instalação, ou mesmo continuidade, dos esforços tecnológicos locais por parte da empresas, especialmente das multinacionais. A despeito de não beneficiar todo o conjunto de empresas selecionadas para a pesquisa de campo, uma vez que o tipo de isenção previsto não se aplica às software houses, a importância de Lei se revela pelo fato de beneficiar as maiores empresas presentes no pólo, que potencialmente liderariam iniciativas voltadas à articulação dos demais agentes locais.

No entanto, destacar a existência de significativas atividades voltadas para a pesquisa e desenvolvimento nessa região, bem como identificar na Lei de Informática sua principal motivação, não significa deixar de apresentar considerações críticas com relação aos seus resultados efetivos.

Pretende-se aqui avançar na caracterização das atividades tecnológicas do pólo, apontando inclusive para as limitações que as caracterizam na criação de um ambiente mais propício para o florescimento de novos empreendimentos de base tecnológica e de interações mais intensas entre os atores já existentes.

O trabalho apresenta na seção 2 os aspectos principais que caracterizam o instrumento de fomento à atividade tecnológica mais relevante para a compreensão da dinâmica tecnológica local (a Lei de Informática). Posteriormente, a seção 3 apresenta um breve histórico da constituição do pólo e a seção 4 procura analisar a dinâmica de interaçóes entre os agentes vigente até meados 
dos anos 1990. A seguir, o trabalho mostra uma caracterização da estrutura produtiva local e os resultados da pesquisa de campo (seção 5). Finalmente na seção 6 é apresentado o diagnóstico da atual configuração das interações entre os agentes locais nesse novo ambiente e na seção 7 são tecidas algumas considerações finais.

\section{A Lei de Informática como instrumento indutor de atividades tecnológicas}

A Lei de Informática é atualmente um dos mais relevantes instrumentos do arcabouço institucional em que se inserem as empresas do complexo eletrônico no Brasil. A importância desta verifica-se não apenas pelo elevado montante de recursos envolvidos (sob as formas de renúncia fiscal e de suas contrapartidas), como também pelo seu papel determinante na criação e manutenção de departamentos, laboratórios e institutos de pesquisa. ${ }^{2}$

Mesmo na sua mais recente versão (Lei 11.077, sancionada em 30 de dezembro de 2004), a Lei preserva as mesmas características essenciais da sua forma original (Lei 8.248/91), e resulta de uma necessidade de redefinição da política de informática ajustada ao novo ambiente institucional que se instala com o fim efetivo da reserva em outubro de 1992, caracterizado por uma mudança expressiva rumo a um modelo mais aberto e competitivo.

O protecionismo deu lugar a uma política que visava a remoção de proteções não-tarifárias, bem como a redução no nível e dispersão das alíquotas do imposto de importação. A definição de novas regras para o setor ocorreu com a aprovação da Lei 8.248 em outubro de 1991 e sua vigência efetiva com a regulamentação em 1993. Esta legislação eliminou as restrições anteriores ao capital estrangeiro e definiu uma nova política de estímulo centrada na obrigatoriedade de esforços mínimos em P\&D (equivalentes a 5\% do faturamento) em troca de incentivos fiscais. A Lei definia também a necessária obediência ao PPB (Processo Produtivo Básico), determinando um grau mínimo de nacionalização na manufatura dos produtos incentivados.

\footnotetext{
Segundo os últimos dados consolidados disponíveis, a renúncia fiscal realizada entre 1993 e 2000 somou R\$ 4,4 bilhões, contra uma arrecadação em tributos de $R \$ 8,1$ bilhões no período, referentes à produção das empresas incentivadas, frente a investimentos (de 1993 a 2002) de P\&D da ordem de R\$ 3,3 bilhões. Uma avaliação dos resultados da Lei de Informática foi desenvolvida em Garcia \& Roselino (2004).
} 
Originalmente, a Lei previa a manutenção dos incentivos até 1999. Após alguma indefinição a respeito dos rumos da política para o setor, a Lei foi reeditada com algumas modificações em 2001 (Lei 10.176); esta teria vigência prevista estendida até $2009 .^{3}$

No final de 2004 o governo sancionou uma nova Lei (11.077) em lugar da anterior, estendendo os benefícios até 2019 e incorporando algumas novidades. A principal alteração é a criação de uma diferenciação na porcentagem do incentivo a partir de critérios geográficos e da origem do desenvolvimento do produto. ${ }^{4}$

A partir dessa nova versão definiram-se os seguintes percentuais diferenciados de incentivos sobre o IPI devido: para produtos manufaturados no País, nas regiōes Sul ou Sudeste, conta com redução de $80 \%$ de IPI; caso isso ocorra no Norte, Nordeste e Centro-Oeste, a redução é de 95\%. Para produtos manufaturados e desenvolvidos localmente, o porcentual é maior: nas regiōes Sul e Sudeste, é de 95\%, e para o Norte, Nordeste e Centro-Oeste, a empresa se torna isenta do pagamento de IPI sobre o produto fabricado. Esses porcentuais serão preservados até 2014, quando serão reduzidos progressivamente até a extinção dos mesmos, que ocorrerá em 2019 (Simões, 2005).

\section{Breve histórico da constituição do pólo de TIC da região de Campinas}

Dois eventos merecem destaque como fatores determinantes para a formação do pólo: a instalação da IBM na região no início dos anos 1970 (e sua estratégia de criação e relacionamento com fornecedores), e a criação de instituiçôes públicas de excelência em pesquisa e ensino voltadas às atividades tecnológicas (com ênfase na criação da UNICAMP e do CPqD/Telebrás).

\footnotetext{
A principal modificação foi a exigência da alocação dos investimentos em $P \& D$ seguindo critérios geográficos, com a destinação de uma parte dos recursos (equivalentes à $0,8 \%$ do faturamento) para projetos no Norte, Nordeste e CentroOeste do País. Ademais a Lei trazia a determinação de que uma parte fosse destinada para atividades internas $(2,7 \%$ do faturamento), outra parte em instituições parceiras $(1 \%)$, e o restante destinado ao fundo setorial de informática $(0,5 \%)$.

4 Outra alteração que merece nota é da base de cálculo do faturamento, que deixa de ser o faturamento global da empresa e passa a ser a de cada produto beneficiado. Esta alteração visa corrigir uma distorção das versões anteriores que incentivava as empresas ao artifício de criar diversas "pessoas jurídicas" para cada produto incentivado. Acreditase então que esta alteração não deverá resultar em redução dos valores investidos, uma vez que efetivamente as empresas já se utilizavam desta base de cálculo a partir deste artifício.
} 
Desse modo, em parte devido à sua própria expressão no cenário econômico estadual e nacional, e em parte por apresentar importantes pré-requisitos para o desenvolvimento de atividades intensivas em alta tecnologia, o pólo de TIC de Campinas remonta suas origens ao início da década de 1970. Com o estabelecimento pioneiro da IBM na região em 1971 iniciou-se, ainda que gradativamente, um movimento de atração de novas empresas de alta tecnologia para o pólo.

Com a estratégia de incentivar a criação de capacidades em empresas locais, a fim de desenvolver uma articulada rede de fornecedores, as empresas pioneiras (principalmente a IBM) trouxeram importantes estímulos para o desenvolvimento do pólo. Primeiramente, propiciaram “... a incorporação de alguns desses produtores locais, muitos de pequeno e médio porte, à rede de firmas fornecedoras e prestadoras de serviço das empresas líderes, de modo a configurar um processo extensivo de divisão do trabalho entre eles". Em segundo lugar, possibilitaram “.... formação de um contingente razoável de trabalhadores especializados, com habilidades tácitas específicas" (Souza \& Garcia, 1998:419), os chamados “ibemistas".

Os "ibemistas" na medida em que trocaram seus empregos na IBM por outros em empresas locais, ou mesmo criaram suas próprias empresas, constituíram-se em um importante mecanismo de transmissão do conhecimento tácito no pólo. A partir de então, intensificaram-se o aprendizado coletivo e a capacidade inovativa da região o que, por sua vez, trouxe impulsos para a atração de novas empresas.

Com o estabelecimento do CPqD na região em 1980, o pólo passou a destacar-se nacionalmente. Numa estrutura em que o mercado de telecomunicações era dominado pelo monopólio da Telebrás, a localização do CPqD na região tornou-se um grande incentivo para a atração de novas empresas.

Uma vez que as diretrizes da política estatal para o setor de telecomunicaçôes faziam várias exigências quanto ao grau de nacionalização das tecnologias utilizadas pelos fornecedores de equipamentos, a proximidade com o CPqD era vista como uma questão estratégica pelas empresas multinacionais estabelecidas no Brasil. Ou seja, tais empresas observaram que essa proximidade geográfica configuravase como um elemento essencial para a disseminação do conhecimento tácito e para o decorrente processo de aprendizado tecnológico e inovativo de suas filiais. 
Ademais, vale destacar que a política de compras centralizada em um único órgão também conferia papel fundamental ao estabelecimento de boas relações com o CPqD. Além de alavancar a atração de novas empresas, o CPqD contribuiu para fomentar a capacidade inovativa do pólo, pois “...desenvolveu localmente os principais avanços da indústria nacional de telecomunicaçôes, como as centrais digitais trópico e a produção pioneira de fibras óticas no país" (Suzigan et al., 2001:34).

Nesse movimento de atração de novas empresas e criação de capacidades tecnológicas e inovativas, também cabe destacar a importância da presença de inúmeras instituiçôes locais, como universidades, laboratórios, centros de pesquisa e órgãos públicos locais de apoio às novas entrantes. A atuação dessas instituiçōes, além da importância para o aprendizado inicial, ainda se constitui como uma das principais características do pólo. ${ }^{5}$

Destacando-se entre essas instituições encontra-se a UNICAMP - Universidade Estadual de Campinas. Instalada em 1966, tal instituição conta com diversos institutos, faculdades e laboratórios voltados para as áreas de engenharia e física. A reconhecida reputação nacional destaca a UNICAMP, sobretudo pela forte ênfase em pesquisas de caráter tecnológico e pela formação de recursos humanos altamente qualificados.

Também vale destacar a presença no pólo da PUCCamp - Pontifícia Universidade Católica de Campinas, e de outras instituiçóes de ensino superior e técnico, as quais também desempenharam e ainda desempenham um importante papel na formação de mão-de-obra qualificada (Tabela 1).

Em relação às instituições de apoio e suporte, pode-se afirmar que estas também contribuíram para a consolidação do pólo (ainda que com um papel secundário em alguns casos), seja por meio da busca de criação de capacidades locais, seja por meio do incentivo à atração de novas empresas. Dentre as primeiras cabe destacar o Centro Tecnológico para Informática (atual CenPRA) criado em 1984 e o Laboratório Nacional de Luz Síncroton (atual ABTLuS) criado em 1987. Dentre as segundas destacam-se iniciativas como a criação em 1983 da CIATEC - Companhia de Desenvolvimento do Pólo de Alta Tecnologia de Campinas, criada "com o objetivo de coordenar as ações entre as empresas,

\footnotetext{
Segundo dados do MTE-RAIS 2002, para a classe 73.105 - Instituições de P\&D das ciências físicas e naturais - a região de Campinas possui, excetuando-se as universidades, 11 estabelecimentos que empregam 1.347 pessoas.
} 
TABELA 1

Número de estabelecimentos das instituições de P\&D e de Educação na microrregião de Campinas, 2002.

\begin{tabular}{lccc}
\hline Classe CNAE & Descrição & $\begin{array}{c}\text { Número de } \\
\text { empregos }\end{array}$ & $\begin{array}{c}\text { Número de } \\
\text { estabelecimentos }\end{array}$ \\
\hline 73.105 & Instituiçães de P\&D & 1.347 & 11 \\
80.314 & $\begin{array}{c}\text { Educação Superior - Graduação } \\
80.322\end{array}$ & 556 & 17 \\
80.330 & $\begin{array}{c}\text { Educação Superior - Graduação e } \\
\text { Pós-Graduação } \\
80.969\end{array}$ & 16.044 & 3 \\
& $\begin{array}{c}\text { Educação Superior - Pós Graduação e } \\
\text { Extensão }\end{array}$ & 601 & 12 \\
\hline
\end{tabular}

de modo a estimular a implantação de empresas de base tecnológica na cidade, e de intermediar as relações entre as empresas, a universidade e os institutos de pesquisa" (Souza \& Garcia, 1998:411). A despeito da operação de um significativo número de empresas nesse local, a CIATEC não conseguiu desempenhar plenamente suas funções de articulação entre empresas e demais instituições tecnológicas. Porém, sua criação demonstrou aos possíveis entrantes a existência de um comprometimento do governo local para com o fomento do pólo (Porto et al., 2000:5).

Em uma fase posterior, com a consolidação do pólo, outras instituições instalaram-se na região, dentre as quais destacam-se o Agente Local e a Coordenação Nacional do SOFTEX. Concentrado no suporte às empresas locais de software, essas instituiçóes serviram menos como atrativo a novas entrantes do que como órgãos representativos de interesses setoriais, dando organicidade para o conjunto, anteriormente disperso de pequenas e médias software houses locais.

Em síntese, pode-se afirmar que a soma desses fatores ao estabelecimento da IBM e do CPqD foram os grandes responsáveis pela atração de uma primeira onda de empresas. As interações entre essas empresas e a IBM e CPqD, por sua 
vez, tiveram grande importância para a consolidação do aprendizado tecnológico e inovativo local na primeira fase de desenvolvimento do pólo.

\section{Dinâmica de interações entre os agentes do pólo no período pré-privatização do Sistema Telebrás}

No período entre o estabelecimento pioneiro da IBM na região em 1971 até a privatização do Sistema Telebrás em meados da década de 1990, o pólo caracterizou-se principalmente pelo desenvolvimento tecnológico a partir de um modelo amparado no setor estatal.

Conforme afirmam Rama et al. (2002:6) ao citarem Markusen (1996), tal modelo caracteriza-se como aquele em que “...grande parte do estímulo de um pólo deriva de uma ou algumas instituições estatais, como (...) laboratórios de pesquisa, universidades ou da proximidade de capitais nacionais". Desse modo, nessa primeira fase agentes como CPqD e UNICAMP foram de fundamental importância para o estímulo ao aprendizado coletivo e à criação de capacidades inovativas no pólo.

O CPqD, na medida que concentrava a atividade de P\&D do Sistema Telebrás, atuava como um centro irradiador de conhecimento para as empresas instaladas no pólo. Essas empresas, uma vez que estavam sujeitas às exigências quanto às especificidades das tecnologias a serem utilizadas, norteavam suas ações a partir das diretrizes da política de compras do Sistema Telebrás. Ou seja, dado o poder do CPqD de influenciar tanto a atividade de compra do Sistema Telebrás quanto de determinar os padrões tecnológicos a serem adotados, tal instituição exercia grande influência sobre a dinâmica tecnológica do pólo.

A UNICAMP, por sua vez, além de desempenhar importante papel na formação de mão-de-obra qualificada, estabelecia inúmeras parcerias com o CPqD. Paralelamente, também desenvolvia projetos com empresas do pólo direcionados principalmente para a área de pesquisa básica.

Desse modo, "durante toda a década de 1980, o CPqD e a UNICAMP funcionaram como centros difusores de efeitos spillovers e spinoffs, resultando na criação de empresas que gravitavam em torno dos projetos desenvolvidos" (Suzigan et al., 2001:34) (Figura 1). Tal fato nos mostra que "a origem das empresas nacionais no período do monopólio estatal é normalmente explicável como parte desses efeitos" (Suzigan et al., 2001:34). 
FIGURA 1

Dinâmica de interações entre os agentes do pólo - década de 1980 a meados de 1990

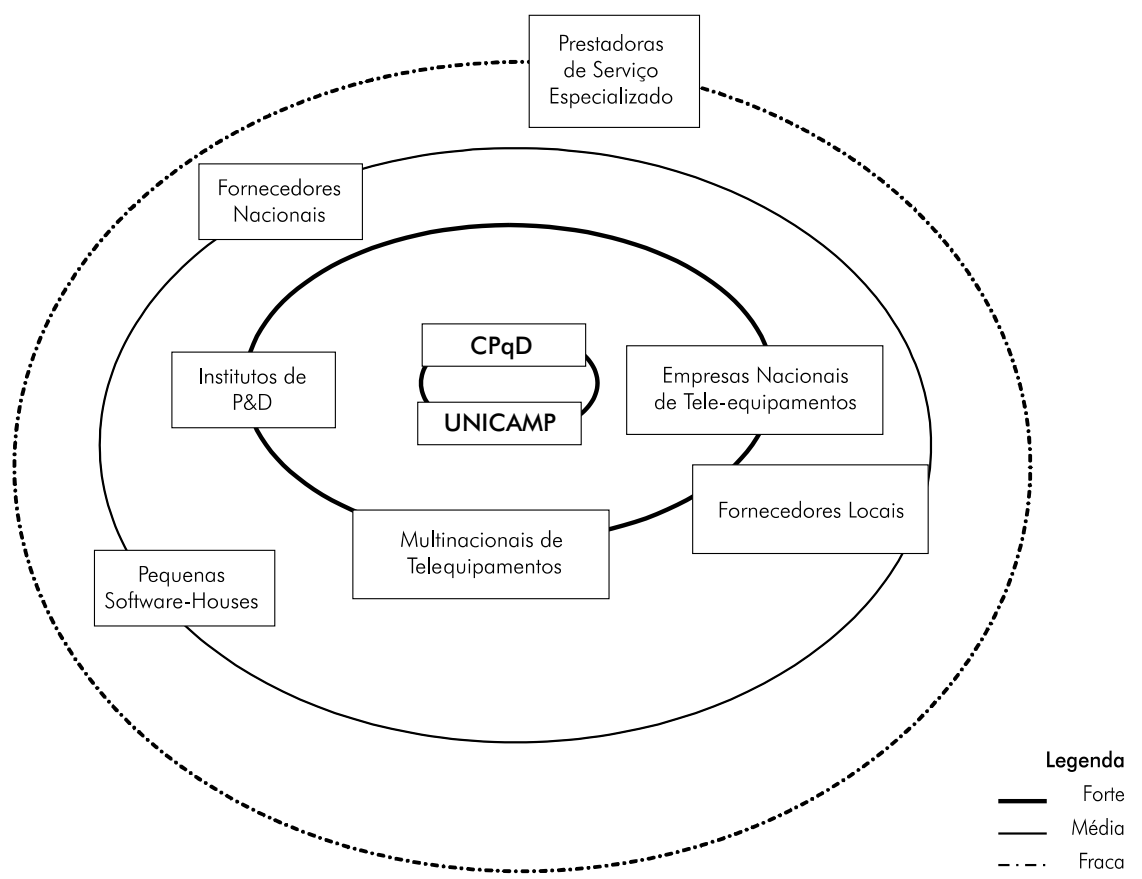

Fonte: elaboração própria.

A partir de tal modelo, várias empresas nacionais consolidaram-se, inclusive em segmentos (como desenvolvimento de teleequipamentos) intensivos em P\&D e com a presença de grandes players globais. A vigência desse modelo por mais de uma década fez com que o pólo se caracterizasse como um grande centro de desenvolvimento tecnológico nacional.

Uma vez que a dinâmica de funcionamento do pólo exigia quase que compulsoriamente a presença do $\mathrm{CPqD}$ em muitos projetos tecnológicos, as interações intensificaram-se, contribuindo para a difusão do conhecimento tácito e para a potencialização do processo inovativo local. Atuando no sentido de intensificar essas interações, destacou-se a presença de uma alta taxa de rotatividade dos funcionários entre empresas e instituições. Ou seja, como grande parte dos 
principais cargos das empresas de TIC passaram a ser ocupados por ex-funcionários da UNICAMP e do CPqD (Suzigan et al., 2001); o desenvolvimento de códigos comuns de comunicação facilitou a transmissão do conhecimento tácito.

Em síntese, pode-se afirmar que a vigência do modelo estatal durante uma década mostrou-se uma condição sine qua non ao fortalecimento da capacidade inovativa do pólo, principalmente no que tange às empresas nacionais.

\section{Caracterização produtiva e tecnológica do pólo}

\subsection{Identificação das empresas e demais atores relevantes na atual configuração do pólo}

Como efeito do processo de privatização do Sistema Telebrás, a atividade de TIC desenvolvida no pólo de Campinas sofreu grandes mudanças. Tais mudanças afetaram tanto a organização da estrutura produtiva quanto a dinâmica de aprendizado local, criando uma segmentação entre os agentes do pólo. O que se observou a partir dessa segmentação foi a substituição do mecanismo de interação e aprendizado vigente no período pré-privatização por outro, no qual fica patente a divisão dos agentes em dois grupos com dinâmicas distintas: o grupo de empresas nacionais e o de multinacionais. ${ }^{6}$

Assim, ao se analisar tal configuração notar-se-á uma certa dualidade no desenvolvimento da atividade de TIC no pólo Campinas. Como os determinantes desses segmentos (multinacionais e nacionais) são essencialmente diferentes, convém analisá-los separadamente.

O grupo das empresas nacionais é composto majoritariamente por empresas de pequeno e médio porte, ${ }^{7}$ as quais têm como principal atividade o desenvolvimento de software. A maioria dessas empresas originou-se como spinoff de instituiçôes locais como a UNICAMP e o CPqD.

Pode-se afirmar que as interações entre agentes locais são mais comuns dentre as empresas nacionais do que nas que integram o grupo de multinacionais.

\footnotetext{
6 A partir de uma abordagem sistêmica voltada à avaliação dos resultados do programa SOFTEX, Stefanuto (2004) identifica a existência de um "subsistema das transnacionais" com uma dinâmica separada daquela que envolve os atores nacionais.

7 A assimetria entre os portes das empresas nacionais e multinacionais entrevistadas pode ser visualizada pelo número médio de empregados (no ano de 2003) de cada grupo, sendo de 98 para as nacionais e 1.166 para as multinacionais.
} 
Tal fato decorre de alguns motivos como: $i$ ) algumas empresas locais terem utilizado em suas fases de consolidação contratos com agentes locais como alavancagem financeira e como um tipo de selo de qualidade; ii) a existência de vínculos (inclusive pessoais) remanescentes do período anterior, que se preservaram no novo ambiente; iii) a necessidade dessas empresas de cooperarem em algumas iniciativas (principalmente as relacionadas ao comércio exterior); e $i v$ ) a maior adequação das estruturas das instituições de apoio e suporte às necessidades de empresas de pequeno e médio portes.

O grupo das multinacionais é composto por empresas de grande porte que concentram sua atuação no setor de equipamentos para telecomunicações. A maioria dessas empresas instalou-se no pólo em meados da década de 1990 depois da criação da Lei de Informática e da privatização do Sistema Telebrás. As empresas multinacionais têm escassas parcerias com agentes do pólo para o desenvolvimento tecnológico. Vale destacar que estas empresas, devido às exigências da Lei de Informática, estabeleceram algumas parcerias tecnológicas com institutos de P\&D locais. ${ }^{8}$

Em relação às instituições locais, as empresas do grupo das multinacionais mantêm algumas parcerias com a UNICAMP (treinamento e qualificação de mãode-obra) e com o CPqD (análises e projeções acerca das transformações do arcabouço institucional do setor e P\&D em atividades tecnológicas secundárias).

Nesse contexto, a amostra deste trabalho procurou escolher empresas que possibilitassem a compreensão das características dos dois grupos nos quais a atividade de TIC é desenvolvida. Ela foi composta por seis empresas e duas instituições (SOFTEX e CPqD). Dessas empresas três são do grupo das multinacionais e três do grupo das locais.

Como critério de seleção para as empresas multinacionais, optou-se por levar em consideração fatores como i) realização de atividades de P\&D no pólo; ii) faturamento; e iii) potencial para o estabelecimento de interações com empresas locais, dada a atuação em segmentos semelhantes.

Levando em conta esses critérios, foram escolhidas uma empresa de origem norte-americana (Motorola), uma sueca (Ericsson) e uma canadense (Nortel

8 Denota-se que a difusão do aprendizado coletivo local acaba prejudicada porque as empresas beneficiam-se de um artifício que acaba por "internalizar" de facto parte dos esforços desenvolvidos formalmente por instituições parceiras mediante a criação de institutos de pesquisa formalmente independentes, com as quais se estabelecem vínculos quase exclusivos (para uma leitura mais aprofundada desta questão ver Garcia \& Roselino, 2004). 
Networks). Todas essas empresas estabeleceram-se no pólo a partir de meados da década de 1990, e têm sua principal atuação centralizada no segmento de telequipamentos. Uma delas concentra-se majoritariamente na produção de terminais celulares, enquanto que das outras duas, uma concentra-se na produção de estações rádio-base e outra no desenvolvimento do software para infraestrutura de telecomunicações.

Para a escolha das empresas do grupo das nacionais optou-se por utilizar os seguintes critérios de seleção: $i$ ) faturamento; ii) reconhecimento no pólo e reconhecimento nacional e iii) realização de atividades de P\&D no pólo e iv) potencial para o estabelecimento de interações com empresas locais, dada a atuação em segmentos semelhantes.

Foram escolhidas três empresas (Ci\&T, Software Design, CelPlan) e uma fundação (CPqD), todas com algum tipo de relação com os demais agentes do pólo (principalmente em relação à sua criação e aos primeiros contratos). Destas três empresas, a maior é uma integradora de software fornecendo soluções para uma gama de setores muito diversificada, enquanto que a menor desenvolve software para planejamento de estrutura de telecomunicação celular. A terceira empresa atua no desenvolvimento de softwares para o mercado financeiro e a fundação desenvolve software e presta serviços tecnológicos para uma enorme diversidade de segmentos, com especial ênfase para telecomunicações. Vale observar que o fato das empresas nacionais escolhidas concentrarem-se na atividade de software justifica-se principalmente devido ao potencial de interação dessa atividade com as demais empresas do grupo das multinacionais, uma vez que o software (principalmente embarcado) é um dos principais componentes das atividades de telecomunicaçóes.

Somadas, as empresas dos dois grupos têm uma ampla representatividade sobre as atividades de TIC do pólo, uma vez que empregam quase 4.900 pessoas, ou seja cerca de um terço do total dos empregados na atividade de TIC no pólo (Tabela 2).

Quanto às instituições locais, optou-se pela escolha do SOFTEX, dado sua potencialidade em atuar como agente coordenador das interaçôes locais. A fim de compreender as relações entre a instituição e os demais agentes do pólo, foram realizadas duas entrevistas: uma no Agente Local (Núcleo Softex) e outra junto à Coordenação Nacional (ambos localizados em Campinas). 
TABELA 2

Número de empregos e estabelecimentos nas atividades de TIC na região de Campinas e no Estado de São Paulo, 2002

\begin{tabular}{|c|c|c|c|c|c|}
\hline \multirow[b]{2}{*}{ Classe } & \multirow[b]{2}{*}{ Descrição } & \multicolumn{2}{|c|}{$\begin{array}{l}\text { Micro região de } \\
\text { Campinas }\end{array}$} & \multicolumn{2}{|c|}{$\begin{array}{l}\text { Total no } \\
\text { Estado }\end{array}$} \\
\hline & & Emprego & Estab. & Emprego & Estab. \\
\hline 30112 & $\begin{array}{l}\text { Fabricação de máquinas de escrever e calcular, copiadoras } \\
\text { e outros equipamentos não-eletrônicos para escritório }\end{array}$ & 0 & 0 & 69 & 11 \\
\hline 30120 & $\begin{array}{l}\text { Fabricação de máquinas de escrever e calcular, copiadoras } \\
\text { e outros equipamentos eletrônicos destinados a automação } \\
\text { gerencial e comercial }\end{array}$ & 721 & 5 & 1.173 & 41 \\
\hline 30210 & Fabricação de computadores & 192 & 8 & 3.275 & 83 \\
\hline 30228 & $\begin{array}{l}\text { Fabricação de equipamentos periféricos para máquinas } \\
\text { eletrônicas para tratamento de informações }\end{array}$ & 511 & 9 & 5.274 & 148 \\
\hline 31305 & Fabricação de fios, cabos e condutores elétricos isolados & 559 & 14 & 8.968 & 209 \\
\hline 32107 & Fabricação de material eletrônico básico & 2.002 & 37 & 15.313 & 439 \\
\hline 32212 & $\begin{array}{l}\text { Fabricação de equipamentos transmissores de rádio e televisão } \\
\text { e de equipamentos para estações telefônicas, para radiotelefonia } \\
\text { e radiotelegrafia - inclusive de microondas e repetidoras }\end{array}$ & 1.042 & 14 & 3.075 & 98 \\
\hline 32220 & $\begin{array}{l}\text { Fabricação de aparelhos telefônicos, sistemas de } \\
\text { intercomunicação e semelhantes }\end{array}$ & 2.399 & 10 & 5.031 & 125 \\
\hline 32301 & $\begin{array}{l}\text { Fabricação de aparelhos receptores de rádio e televisão } \\
\text { e de reprodução, gravação ou amplificação de som e vídeo }\end{array}$ & 261 & 8 & 3.861 & 108 \\
\hline 33200 & $\begin{array}{l}\text { Fabricação de aparelhos e instrumentos de medida, teste } \\
\text { e controle - exceto equipamentos para controle de } \\
\text { processos industriais }\end{array}$ & 129 & 4 & 3.863 & 120 \\
\hline 33308 & $\begin{array}{l}\text { Fabricação de máquinas, aparelhos e equipamentos } \\
\text { de sistemas eletrônicos dedicados a automação industrial } \\
\text { e ao controle do processo produtivo }\end{array}$ & 342 & 22 & 4.018 & 199 \\
\hline 51616 & $\begin{array}{l}\text { Comércio atacadista de máquinas, aparelhos e equipamentos } \\
\text { para uso agropecuário }\end{array}$ & 55 & 10 & 2.217 & 236 \\
\hline 51640 & $\begin{array}{l}\text { Comércio atacadista de máquinas e equipamentos para o } \\
\text { comércio e escritório }\end{array}$ & 38 & 6 & 2.182 & 199 \\
\hline 51659 & $\begin{array}{l}\text { Comércio atacadista de computadores, equipamentos de } \\
\text { telefonia e comunicação, partes e peças }\end{array}$ & 172 & 3 & 1.582 & 146 \\
\hline 51691 & $\begin{array}{l}\text { Comércio atacadista de máquinas, aparelhos e equipamentos } \\
\text { para usos industrial, técnico e profissional, e outros usos } \\
\text { não especificados anteriormente }\end{array}$ & 1.396 & 174 & 18.263 & 1.870 \\
\hline 64203 & Telecomunicações & 3.015 & 55 & 32.882 & 686 \\
\hline 71331 & Aluguel de máquinas e equipamentos para escritórios & 92 & 5 & 1.344 & 91 \\
\hline 72109 & Consultoria em hardware & 283 & 33 & 14.351 & 879 \\
\hline 72214 & Desenvolvimento e edição de software prontos para uso & 74 & 6 & 1.169 & 146 \\
\hline 72290 & $\begin{array}{l}\text { Desenvolvimento de software sob encomenda e outras } \\
\text { consultorias em software }\end{array}$ & 96 & 19 & 4.664 & 369 \\
\hline 72303 & Processamento de dados & 465 & 55 & 15.489 & 1.450 \\
\hline 72400 & $\begin{array}{l}\text { Atividades de bancos de dados e distribuição on-line } \\
\text { de conteúdo eletrônico }\end{array}$ & 18 & 5 & 2.319 & 85 \\
\hline 72508 & $\begin{array}{l}\text { Manutenção e reparação de máquinas de escritório } \\
\text { e de informática }\end{array}$ & 310 & 38 & 7.519 & 891 \\
\hline 72907 & $\begin{array}{l}\text { Outras atividades de informática, não especificadas } \\
\text { anteriormente }\end{array}$ & 406 & 70 & 16.238 & 1.238 \\
\hline & TOTAL & 14.578 & 610 & 174.139 & 9.867 \\
\hline
\end{tabular}

Fonte: MTE/RAIS, 2002. Elaboração própria. Baseada na classificação adotada por Trullén et al. (2002). 


\subsection{Grupo das empresas multinacionais}

As empresas do grupo de multinacionais, conforme citado anteriormente, instalaram-se no pólo a partir de meados da década de 1990.

Quando questionadas pelos motivos para a instalação no pólo, essas empresas foram unânimes ao citar a disponibilidade de mão-de-obra altamente qualificada. Duas delas também destacaram a importância da existência de um pólo de TIC já consolidado. Além desses fatores também foram lembrados a proximidade com o CPqD e com o mercado consumidor, a presença de uma completa infra-estrutura de telecomunicação e também de transporte, incluindo importantes rodovias e o principal aeroporto internacional de transporte de cargas do Brasil.

Tais empresas concentram suas atividades no segmento de equipamentos para telecomunicações e têm suas estratégias de desenvolvimento local norteadas pelas diretrizes de suas matrizes. Como fazem parte de uma estratégia global de acumulação de capital, as três empresas citaram que seus esforços tecnológicos são subordinados às diretrizes mundiais, e que parte expressiva destes referemse ao desenvolvimento de atividades envolvidas em projetos globais. No entanto, verificou-se um baixo grau de apropriabilidade dos resultados econômicos oriundos de inovações locais. São raros os casos de registro da propriedade intelectual em nome das subsidiárias brasileiras.

Nessa configuração as unidades presentes no pólo além de desenvolverem soluçôes para o mercado local, também realizam esforços conjuntos com outros centros globais de desenvolvimento. Ou seja, uma vez que as três empresas afirmaram possuir mandatos globais em atividades específicas, sempre que estas são requeridas por quaisquer unidades globais do grupo ao qual pertencem, as unidades do pólo direcionam seus esforços para o provimento de soluçóes globais.

Grande parte desses esforços de desenvolvimento de soluçôes (sejam globais ou locais) é concentrada na atividade de P\&D em software, na qual residiria a maior vantagem competitiva brasileira relacionada à indústria de telecomunicações (Queiroz et al., 2003). Uma vez que todas as empresas foram unânimes em afirmar que há uma clara tendência à commoditização do hardware, todas têm concentrado grande parte de seus esforços e investimentos no desenvolvimento de software (o que chega a responder por $80 \%$ dos investimentos em uma delas). 
Assim, conforme lembra Galina (2003:222) observa-se que "hoje, os softwares são os grandes inovadores em telecomunicações, já que permitem flexibilidade e agilidade de sistemas, seja por meio de alterações/adaptações rápidas ou de desenvolvimentos de novos serviços, tornando-se assim - o software - uma ferramenta importante para a competitividade das empresas".

Essas atividades locais de P\&D, por sua vez, só são possíveis em virtude dos benefícios fiscais previstos na Lei de Informática. Apesar de destacarem a existência de uma ampla rede local de instituições de apoio às atividades tecnológicas, as empresas foram unânimes ao condicionar a atividade de P\&D local à existência da Lei. Segundo elas, os benefícios tributários da Lei foram condição sine qua non para o esforço tecnológico local.

Tal fato ocorre porque, uma vez que estão inseridas em cadeias internacionais, as empresas concorrem com outros sites globais para a realização dessas atividades. ${ }^{9}$ Como essa concorrência leva em consideração além de capacidades locais as vantagens de custo, a existência de um mecanismo que confira certo benefício tributário é um importante fator para a capacidade de competição das unidades locais frente outros sites globais. Esse mesmo aspecto é destacado por Gomes (2003:145) ao afirmar que: “(...) a competição interna à corporação não apenas é fomentada pelo lado do comando corporativo que deseja adquirir e renovar capacidades, mas é também encampada pelas próprias subsidiárias que precisam captar fundos para a manutenção e/ou ampliação de seus mandatos e reputaçōes."

A importância desses benefícios intensificou-se ainda mais depois da crise que o setor de teleequipamentos enfrentou a partir do ano de 2001. Com a retração mundial, o setor defrontou-se com um grande movimento de reestruturação, com fechamento de unidades fabris, diminuição do número de empregados e concentração das atividades de $\mathrm{P} \& \mathrm{D}$ em um número menor de sites globais.

Nesse movimento exacerbou-se a concorrência entre esses diversos sites e, além das competências, as vantagens de custo passaram a ter influência fundamental, uma vez que as plantas localizadas no pólo de Campinas passaram a sofrer a competição direta de outras localizadas na Europa Central, na China

9 Uma discussão mais pormenorizada dos fatores de a tração e desempenho de atividades de P\&D desenvolvidas por subsidiárias de empresas multinacionais no Brasil, a partir de uma análise setorial comparativa das indústrias automotiva, farmacêutica e de telecomunicações é apresentada por Costa (2006). 
e na Índia. A soma desses dois fatores (existência de competências locais e de custos relativamente baixos), potencializados pelos incentivos da Lei de Informática, é que garantiu a manutenção das atividades de P\&D no pólo.

Não obstante a importância vital para o desenvolvimento das atividades de P\&D no Brasil, as empresas também foram unânimes em afirmar que realizam gastos neste quesito superiores aos estabelecidos pela Lei. ${ }^{10} \mathrm{Em}$ outras palavras, nota-se que apesar da importância para o estímulo inicial, pode-se acreditar que uma parte da atividade de P\&D local conquistou uma relativa autonomia em relação à Lei de Informática.

Além disso, dada a tendência de crescente commoditização do hardware, a realização de $\mathrm{P} \& D$ voltado ao software (identificado como atividade em que se concentram as competências locais) configura-se cada vez mais como uma estratégia competitiva das empresas de TIC.

Em síntese, o que se observa é que a Lei de Informática conseguiu de certa maneira endogeneizar uma parte do esforço tecnológico local. Ou seja, uma vez que as atividades de TIC são intensivas em conhecimento e têm uma dinâmica altamente inovativa, o esforço de P\&D é um elemento central para a criação de novas capacidades.

Realizando grande parte do P\&D para o desenvolvimento de software como componente embarcado, as empresas presentes na amostra do grupo das multinacionais empregam cerca de 3.500 pessoas, das quais 295 trabalham integralmente no P\&D em software. Se somarmos a esses números os funcionários dos institutos de P\&D parceiros que recebem os recursos da Lei de Informática (e que muitas vezes dividem o mesmo imóvel), chegaríamos com base em uma estimativa conservadora a mais de 600 pessoas trabalhando no P\&D somente em software.

No que diz respeito às interações entre os agentes do pólo, o que fica patente no grupo das multinacionais é que estas empresas concentram grande parte de suas parcerias com institutos de pesquisa locais credenciados pelo MCT - Ministério da Ciência e Tecnologia, para receber recursos estipulados pela Lei de Informática. No entanto, como esses institutos possuem "vínculos umbilicais" com as multinacionais (visto que na sua maioria foram criados por

\footnotetext{
10 Esta afirmação merece ser tomada com alguma prudência pela possibilidade de critérios divergentes para definir os investimentos que devem ser lançados contabilmente na "conta P\&D".
} 
iniciativa das próprias empresas), as interações com os demais agentes locais são inibidas. Além disso, como alguns desses institutos chegam até a ocupar as mesmas instalações das empresas com as quais mantêm parcerias, a difusão do conhecimento tácito para outros agentes do pólo também fica prejudicada.

Ao se analisar essa situação, o que se verifica são algumas deformações provocadas pela própria da Lei de Informática. Devido às exigências de se desenvolver parte do esforço de P\&D externamente, o que se observou foi uma estratégia das multinacionais de patrocinarem a fundação de institutos de pesquisa, fazendo com que estes fiquem muito próximos a elas. Desse modo, conseguem cumprir as exigências previstas na Lei e ao mesmo tempo apropriam-se de maior parte dos esforços de P\&D desenvolvidos "externamente". Tal fato é também destacado por Galina (2005:23): "Vale salientar uma característica também muito comum entre as empresas, que é a criação de seus próprios centros ou fundações de pesquisa, que, por mais que as empresas neguem, servem, de alguma forma, para externalizar a pesquisa que seria realizada internamente e, com isso, prestar contas dos recursos exigidos pela Lei de Informática para pesquisas fora dos muros das companhias.”

Esse mecanismo de apropriação acabou se constituindo como uma dupla vantagem para as empresas. Primeiro porque, por meio da interação com institutos de P\&D, que contam com um corpo técnico capacitado, propicia a criação de novas capacidades. Como estas não são difundidas para os demais agentes do pólo, acabam transformando-se em importantes vantagens competitivas da empresa em questão. Em segundo lugar porque o caráter muitas vezes contínuo dessas parcerias facilita a transmissão do conhecimento tácito entre empresas e institutos, fazendo com que estes últimos estejam cada vez mais aptos a desenvolver soluções adequadas às especificidades da empresa parceira.

Paralelamente, o estabelecimento de outras parcerias com agentes locais diminui. Das empresas entrevistadas, duas delas citaram somente parcerias relevantes com o CPqD e com a UNICAMP, enquanto a outra destacou como parceiras na atividade de P\&D instituições localizadas fora do pólo (como o Instituto Cesar da UFPE). Vale destacar que somente uma delas afirmou realizar interações com software houses locais. Mesmo assim, tais interações são esporádicas e têm como objetivo a resolução de problemas pontuais, e não o desenvolvimento tecnológico conjunto. 
Apesar de CPqD e UNICAMP ainda serem citados como parceiros, nota-se que apenas uma das empresas afirmou que as atividades desenvolvidas em conjunto têm caráter tecnológico. Ou seja, cada vez mais o CPqD é visto como um parceiro institucional (e em alguns casos até mesmo como concorrente), ao passo que à UNICAMP são atribuídas funções principalmente no que tange à formação de mão-de-obra.

Quando são questionadas sobre os eventuais efeitos de spin-offs que poderiam ocasionar, as empresas multinacionais invariavelmente relatam a sua inexistência. Além disso, ainda afirmam que não oferecem a seus funcionários incentivos para a formação de empresas em atividades complementares. Essa falta de incentivo é justificada em grande parte pelo fato das empresas conceberem essa prática mais como uma ameaça à sua posição de mercado do que como a possibilidade de consolidação de um potencial aliado estratégico, o qual poderia atuar futuramente em parcerias que possibilitem o desenvolvimento tecnológico complementar.

Em síntese, assim como ocorre em relação às parcerias, pode-se afirmar que em relação aos spin-offs as entrevistadas não se comportam de maneira a impulsionar a difusão do conhecimento. É justamente nesse ponto que reside a maior fragilidade da Lei de Informática.

No que diz respeito às demais instituiçõos locais (como CenPRA, CIATEC, SOFTEX) nota-se que há um certo consenso entre as entrevistadas de que a contribuição destas para a criação de novas capacidades locais é muito reduzida. Tal fato decorre em grande parte da relativa inadequação da estrutura organizacional dessas instituições em relação às necessidades das empresas multinacionais.

Essa mesma inadequação também foi citada pelas entrevistadas em relação aos programas estatais de financiamento tecnológico. Apesar de reconhecerem sua importância, as empresas multinacionais afirmam que tais programas não se enquadram em suas necessidades.

Outros fatores tradicionalmente criticados, como excesso de burocracia e imprevisibilidade, também foram citados como empecilhos para a obtenção de financiamentos públicos. Além disso, apesar das taxas de juros serem competitivas quando comparadas às praticadas no mercado nacional, a obtenção de recursos diretamente com a matriz muitas vezes é mais rápida e mais barata. 
Como sugestôes à política governamental de financiamento tecnológico levantaram-se pontos como a necessidade de se terminar com o contingenciamento do FNDCT - Fundo Nacional de Desenvolvimento Científico e Tecnológico, e direcionar uma parte maior desses recursos para as empresas, além da necessidade de se estabelecer um programa de isenção de impostos na importação de máquinas e equipamentos para a realização de atividade de $\mathrm{P} \& \mathrm{D}$.

Ainda no que diz respeito à política industrial, além da importância da Lei de Informática, procurou-se questionar as novas diretrizes de incentivo à atividade de software presentes na PITCE (Política Industrial Tecnológica e de Comércio Exterior), que elegeu como objetivos prioritários a ampliação das exportações brasileiras de software e a presença das empresas nacionais no mercado doméstico. Observou-se que há um certo receio por parte das empresas quanto aos potenciais efeitos dessas medidas. Além disso, acredita-se que tais diretrizes aplicam-se prioritariamente às pequenas e médias empresas.

\subsection{Grupo das empresas nacionais}

As empresas componentes da amostra do grupo de nacionais concentram suas atividades no desenvolvimento de software e são de portes distintos (uma pequena, uma média e outra grande).

Com uma baixa média de idade, a maioria das empresas entrevistadas foi criada entre finais da década de 1980 e meados da década de 1990. Duas delas foram criadas por ex-alunos do Instituto de Computação da UNICAMP e uma por ex-funcionários do CPqD e da Elebra envolvidos no projeto Trópico.

A trajetória dessas empresas, na medida em que desde a sua fundação estiveram de certa forma ligadas a outros agentes do pólo, apresentou um maior grau de interação local quando comparado às empresas do grupo das multinacionais.

Como as entrevistadas não utilizaram mecanismos de financiamento estatais em sua origem (com exceção de uma), sua consolidação amparou-se em contratos com outros agentes do pólo - principalmente CPqD e IBM. Paralelamente a esses contratos nota-se, pelo menos em sua fase inicial, o estabelecimento de algumas parcerias para o desenvolvimento tecnológico conjunto. Além da importância para o aprendizado e para a alavancagem financeira, as 
entrevistadas destacaram que tais parcerias serviram como importantes credenciais para a obtenção de novos contratos.

Posteriormente, já estando consolidadas, as empresas passaram a identificar como as principais vantagens do pólo de TIC de Campinas não mais a interação com outros agentes locais, e sim a presença de mão-de-obra qualificada e a proximidade com o maior centro consumidor do País. Um indicativo dessa situação é que atualmente apenas duas das empresas afirmaram possuir parceria com o CPqD e, só uma delas atribuiu a essa parceira uma certa importância no que tange ao aprendizado tecnológico.

Em relação às parcerias com outras empresas do pólo, duas empresas da amostra disseram que (além da participação no consórcio de exportação Act Minds) ${ }^{11}$ mantém interaçooes locais. Mas somente em um desses casos essas parcerias são citadas como uma possível fonte de aprendizado e aumento da capacidade inovativa.

Do mesmo modo, ao se analisar as interações com as demais instituições do pólo nota-se que, assim como ocorre no caso do grupo das multinacionais, tais instituiçôes não desempenham grande influência nos processo de aprendizado e inovação. Fato este que está, de certa maneira, relacionado com a política de interações realizada pelas multinacionais. Como essas procuram se apropriar "privadamente" dos benefícios decorrentes das interações obrigadas pela Lei de Informática, as empresas nacionais têm dificuldades de se aproveitar do esforço tecnológico local.

Assim, apesar da potencial importância dos institutos de P\&D beneficiados pela Lei de Informática para a difusão do conhecimento, as empresas da amostra de nacionais afirmaram não desenvolver interações importantes para aprendizado tecnológico com esses agentes. Ou seja, as interaçōes na maioria das vezes restringem-se à discussão de assuntos institucionais do setor.

Esse fato de certa maneira corrobora a análise desenvolvida na seção anterior, qual seja, a de que tais instituições não conseguem impulsionar nem as interações entre agentes nem um processo de aprendizado coletivo local.

Isso ocorre porque, conforme já fora citado anteriormente, grande parte

\footnotetext{
1 As empresas que participam do Act Minds são Ci\&T Software S/A, GrupoNet Teleinformática Ltda, HST Equipamentos Eletrônicos Ltda, IPS Informação e Planejamento em Saúde Ass. Com. Ltda, Prógonos Consultoria \& Comércio Ltda, Programmer's Informática Ltda, Software Design Informática Ltda, SER Informática Desenvolvimento e Comércio Ltda e TeleDesign Serv. e Com. de Telecomunicações Ltda.
} 
dos esforços desenvolvidos por essas instituições acaba ocorrendo em decorrência da necessidade de se cumprir os pré-requisitos formais da Lei de Informática. Em outras palavras, muitas vezes tais institutos servem como um instrumento para que os resultados dos esforços de P\&D desenvolvidos "externamente" sejam absorvidos não pela maioria dos agentes do pólo e sim por suas empresas financiadoras.

Do mesmo modo, as interações com as empresas do grupo de multinacionais são descontínuas e têm pouca ênfase no esforço tecnológico conjunto. Na maioria das vezes estas interações limitam-se à resolução de problemas técnicos pontuais assim como à prestação esporádica de soluções tecnológicas muito específicas (nas quais eventualmente as parceiras tenham competência amplamente reconhecida).

Quando questionadas sobre a importância dos agentes locais de apoio e suporte, as empresas se prontificam a responder de imediato que tais agentes são importantes. Todas elas destacam que são sócias do SOFTEX e que o consideram um órgão que detém o poder de sinalizar politicamente as intenções do setor. No entanto, não o citam como um agente capaz de fomentar o aprendizado coletivo e a capacidade inovativa do pólo.

Empregando cerca de 1.400 pessoas, o grupo de empresas nacionais possui a maior parte de seus clientes localizada fora do pólo. Potencializadas pelo reconhecimento nacional em seus respectivos segmentos de atuação, todas as empresas componentes da amostra têm tido iniciativas no sentido de alcançar o mercado internacional. Tais iniciativas podem ser personificadas pela participação de duas dessas empresas no já citado consórcio de exportação local (Act Minds), o qual é composto por cerca de 700 empregados distribuídos em nove empresas, com faturamento somado de R \$ 32 milhóes em 2002.

Por meio desse consórcio as software houses locais buscam entrar nos mercados dos Estados Unidos, do Japão e da Europa como uma única empresa. Também buscam incentivar a interação e o aprendizado tecnológico entre as parceiras. Desse modo, fortalecem seu poder de competição e têm a possibilidade de oferecer um portfolio completo aos potenciais clientes.

Como grande parte dos entraves relacionados ao estabelecimento no mercado internacional decorre da pequena dimensão das empresas nacionais, tal iniciativa conjunta merece destaque, pois aumenta a competitividade e atua como 
um importante indicativo do potencial de cooperação entre as empresas do pólo. Contando com recursos da APEX - Agência de Promoção de Exportaçôes do Brasil, o consórcio procura ao mesmo tempo introduzir a marca do software brasileiro no mercado exterior (incentivando a presença e a divulgação em eventos internacionais) e viabilizar oportunidades de negócio para as empresas locais.

Não obstante a já notada diversidade presente entre as empresas componentes dessa amostra, as chamadas software houses do pólo de TIC de Campinas tendem a apresentar uma concentração no desenvolvimento de software como serviço de alto valor e como produto customizável.

Essa concentração indica a tendência de busca por uma maior agregação de valor em suas atividades. Tal tendência é confirmada pelo fato de que todas as entrevistadas foram unânimes em afirmar que suas estratégias têm o intuito de fazer com que os produtos de software (em vez de serviços) sejam os principais responsáveis pelo faturamento das empresas. Uma das entrevistadas possui uma estratégia tão avançada nesse sentido que está planejando a criação de uma outra empresa unicamente voltada para o desenvolvimento de produtos.

No que diz respeito aos determinantes da competitividade da atividade de software, as software houses citaram fatores como a componentização e o re-uso (que são elementos fundamentais para a estratégia de ênfase em produtos), além da disponibilização de um completo portfolio e do fato deste estar atualizado com o padrão tecnológico. A atualização do padrão, por sua vez, depende fundamentalmente da intensidade das interações com outras empresas correlatas e da capacidade dessas interaçóes potencializarem o aprendizado tecnológico.

Outro fator de crucial importância para a competitividade das empresas de software é a disponibilidade de capital para a aquisição de empresas que dominem tecnologias correlatas, fator esse que se torna imprescindível para a entrada nos mercados internacionais. Ou seja, dada a enorme segmentação da atividade de software, os mecanismos de fusão e aquisição caracterizam-se como uma das principais fontes de aprendizado inovativo. Não obstante essa importância, nota-se que esse elemento fundamental para a competitividade das empresas do pólo não é objeto de políticas públicas específicas.

Ainda no que diz respeito a essas políticas públicas, as empresas da amostra têm opiniōes divergentes. Enquanto três empresas destacam a importância dos 
programas de financiamento tecnológico, sendo que uma delas utilizou-se em 2002 dos recursos do Prosoft-BNDES e outra recebe importantes quantias dos fundos setoriais, a terceira empresa prefere uma política de autofinanciamento.

Não obstante essa divergência quanto a suas estratégias, existe um consenso geral de que ainda há uma certa incompatibilidade entre os programas estatais de financiamento e as necessidades das empresas. Os entrevistados são enfáticos ao afirmarem que tal fato decorre, em grande medida, da incompreensão das especificidades do setor. Ou seja, os programas ainda se baseiam muito em padrões que se aplicam aos setores manufatureiros, e por isso há muita dificuldade de compreender as características intangíveis e intensivas em conhecimento que a atividade de software apresenta.

Dadas as enormes diferenças entre esses setores, questôes como a exigência de garantias e a limitação dos dispêndios com mão-de-obra freqüentemente inviabilizam potenciais projetos de desenvolvimento de software.

Já em relação às diretrizes da nova política industrial, observa-se um misto de esperança e receio por parte das empresas. Elas salientam a grande importância da atividade de software estar entre as prioridades, uma vez que a atividade ainda carece de uma maior compreensão por parte das autoridades governamentais. Observa-se um certo receio de que o setor volte novamente ao esquecimento sem que as medidas de apoio sejam efetivamente implementadas.

Em síntese observa-se que, com base na avaliação qualitativa das entrevistas, foi possível identificar a conformação de uma dinâmica de interações tecnológicas fundamentalmente distinta da existente no período anterior à privatização do Sistema Telebrás. Em outras palavras, conforme lembram Cassiolato et al. (2002:24), nota-se que há evidências que a reforma estrutural afetou significativamente o comportamento inovativo no nível microeconômico, com importantes conseqüências para o pólo.

Ou seja, além das interações locais terem diminuído quantitativamente quando comparadas ao período pré-privatização (tanto entre empresas nacionais, quanto entre estas e empresas multinacionais), também se denota uma mudança qualitativa em seu caráter. Assim, essas interações deslocaram-se cada vez mais da característica de atuar como instrumentos de aprendizado tecnológico e inovativo, transformando-se em grande parte em contatos exclusivamente comerciais e em discussões acerca dos rumos do arcabouço institucional do setor. 


\section{Diagnóstico da dinâmica de interações no pólo no período pós-privatização}

A privatização do Sistema Telebrás em meados da década de 1990 e a criação da Lei de Informática em 1991 trouxeram profundas mudanças na dinâmica de relacionamento e de aprendizado tecnológico dos agentes do pólo de TIC de Campinas. Tal fato, somado às reformas liberalizantes da década de 1990 e à perspectiva de crescimento do mercado doméstico de telefonia provocou a atração de uma nova onda de investimentos e de novas empresas para a região. Dentre estas se destacam Motorola, Ericsson, Lucent e Nortel Networks.

Nesse novo cenário, o CPqD foi transformado em uma fundação e perdeu grande parte de seu poder de influência sobre o direcionamento dos projetos de desenvolvimento tecnológico do pólo. Ou seja, na medida que a reserva de mercado para produtos nacionais foi abolida, desarticulou-se a política de compras da Telebrás.

Uma vez que essa política era em grande parte a responsável pelas constantes parcerias de desenvolvimento tecnológico entre agentes locais e CPqD, com o seu final, as interações enfraqueceram-se.

Em decorrência, as empresas de capital nacional anteriormente protegidas pela reserva de mercado fragilizaram-se, reduziram investimentos e se concentraram em alguns nichos de mercado. Assim, observou-se um movimento de centralização de capital com as novas multinacionais adquirindo empresas locais como a Zetax, Xtal e Elebra.

Nesse movimento de reestruturação, vários engenheiros e técnicos anteriormente empregados nas empresas de telequipamentos optaram por criar suas próprias empresas, muitas delas concentradas na atividade de software.

Contribuindo para a desarticulação das interações locais, as novas entrantes caracterizaram-se por adotar políticas autônomas de desenvolvimento tecnológico. Segundo Porto et al. (2000:14) essas empresas "parecem conceber uma divisão do trabalho muito clara entre os papéis da universidade, a qual deve estar prioritariamente orientada à formação da mão-de-obra e à pesquisa pura, o papel do $\mathrm{CPqD}$, nas adaptações e parcerias de caráter tecnológico secundário e voltadas principalmente ao desenvolvimento de mercado (e não de tecnologia), e o papel da corporação, como provedora de inovações tecnológicas". 
FIGURA 2

Dinâmica de interação entre os agentes do pólo - período pós-privatização

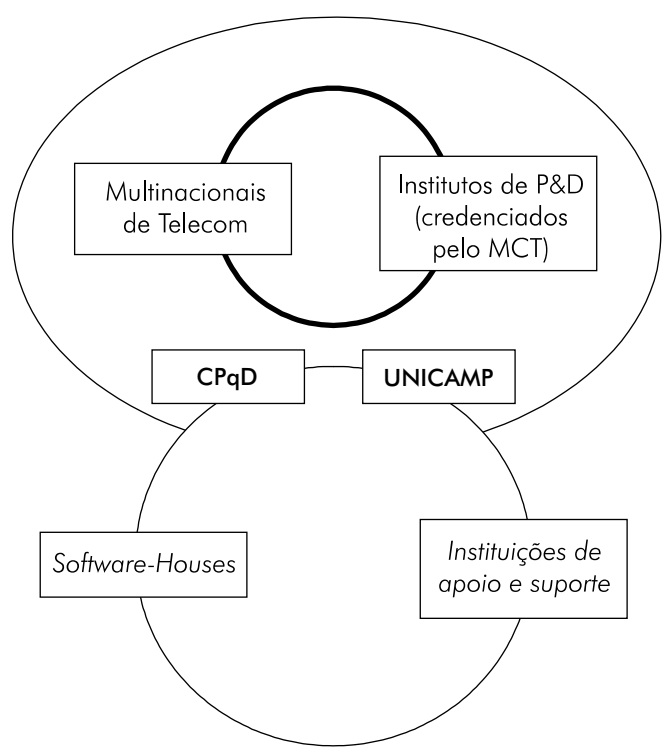

Fonte: elaboração própria.

No que diz respeito à UNICAMP, nota-se uma diminuição no número de projetos desenvolvidos em parceria com empresas locais e com o CPqD. Não obstante, a UNICAMP ainda passou a sofrer alguma concorrência do CPqD, uma vez que este tem realizado em parcerias com empresas locais um número crescente cursos de qualificação e reciclagem de mão-de-obra.

Em síntese, tanto as empresas nacionais quanto as multinacionais diminuíram as atividades com alto potencial inovativo realizadas localmente e aumentaram as atividades com menor conteúdo tecnológico, dentre as quais se destacam a "tropicalização" de produtos estrangeiros e realização de serviços técnicos (Cassiolato et al., 2002:21). Conforme afirmam Porto et al. (2000:10) conclui-se que "em contraste com a situação passada do arranjo, que reconhecidamente 'hospedou' significativas interações de caráter tecnológico, notadamente entre a UNICAMP, o CPqD e as empresas de equipamentos, pode-se dizer que no período recente essas interaçōes enfraqueceram ou, na melhor das hipóteses, mudaram de natureza” (Figura 2). 


\section{Conclusão}

Tendo como marco inicial a instalação de empresas na região no início dos anos 1970, o Pólo TIC de Campinas desenvolveu-se como resultado da combinação das estratégias de constituição de uma rede de fornecedores locais por parte dessas empresas, e de iniciativas oriundas de políticas públicas que resultaram no desenvolvimento de importantes instituições de ensino e pesquisa.

Neste ambiente, constituiu-se uma rede de intensas interações produtivas e tecnológicas entre os agentes que tinham como principais atores centrais o CPqD/Telebrás e a UNICAMP. Nesta configuração (que se manteve até a primeira metade dos anos 1990) floresceram empreendimentos empresariais e tecnológicos que conferiam ao arranjo significativo dinamismo.

A partir das radicais mudanças no arcabouço institucional e no ambiente competitivo que caracterizaram a nova política industrial dos anos 1990, o pólo passou por intensas transformaçôes, com a entrada de novos atores (marcadamente as grandes empresas multinacionais de teleequipamentos), desaparecimento de outros, e sensível redefinição no papel das instituições locais.

A pesquisa de campo que fundamenta este trabalho indicou que as atividades tecnológicas foram, no entanto, preservadas enquanto relevantes neste novo ambiente. As empresas transnacionais visitadas, que respondem por parte majoritária do volume de recursos direcionado às atividades tecnológicas, foram unânimes em destacar o papel decisivo do arcabouço institucional, em particular a "Lei de Informática" como motivação para manutenção dessas atividades.

Graças a esse instrumento, a região continua a mobilizar um grande número de profissionais em atividades tecnológicas formalmente desenvolvidas, nas empresas (nacionais e estrangeiras) e nas demais instituições. No entanto, observou-se uma diferença significativa com relação aos efeitos da Lei de Informática entre os dois grupos (transnacionais e nacionais). Nas primeiras o instrumento mostrou-se eficiente na atração para as unidades locais de parte das atividades tecnológicas globalmente distribuídas, dotando as filiais brasileiras de maior atratividade no processo de escolha da alocação desses esforços definida pela estratégia da corporação. No caso das nacionais, a Lei de Informática tem importância como estímulo adicional para o desenvolvimento de ativida- 
des tecnológicas que são necessárias para a competição nesse setor, ou seja, essas empresas desenvolvem atividades tecnológicas como condição obrigatória para a atuação nesse mercado, e encontram no instrumento da Lei benefícios fiscais que viabilizam financeiramente essas atividades.

O esforço de caracterização dessas atividades aponta, no entanto, para uma sensível alteração com relação à dinâmica existente no período anterior. Identifica-se a existência de dois "subsistemas" de interações que possuem dinâmicas distintas e "quase impermeáveis", tendo no geral vínculos pouco intensos, e um ambiente menos propício ao desenvolvimento tecnológico e inovativo.

Estas considerações apontam para um papel importante da Lei de Informática, na medida em que proporcionou a manutenção de expressivos recursos direcionados às atividades tecnológicas no pólo. Porém, esse instrumento mostrou-se insuficiente para a criação de um ambiente dotado de interações tecnológicas locais mais intensas entre os agentes locais do Pólo TIC de Campinas.

\section{Referências bibliográficas}

Cassiolato, J.E.; Szapiro, M.H.S.; Lastres, H.M.M., "Local system of innovation under strain: the impacts of structural change in the telecommunications cluster of Campinas, Brazil", International Journal of Technology Management, v.25, n.3-4, p.1-26, 2002.

Costa, I., "Technological learning, R\&D and foreign affiliates in Brazil", in Globalization of ReD and Developing Countries, Nova York e Genebra: United Nations, 2006.

Galina, S.V.R., "Desenvolvimento Global de Produtos: O Papel das Subsidiárias Brasileiras de Fornecedores de Equipamentos do Setor de Telecomunicações", tese de Doutoramento, Escola Politécnica, Universidade de São Paulo Poli/USP, 2003.

, "Relatório Setorial Final: Setor Telecomunicações", Relatório de Pesquisa, Diretório de Pesquisa Privada, FINEP, http://www.finep.gov.br/ portaldpp, 2005. 
Garcia, R.C.; Roselino, J.E., "Uma avaliação da Lei de Informática e de seus resultados como instrumento indutor de desenvolvimento tecnológico e industrial", Gestão \& Produção, São Carlos, v.11, n.2, p.1-20, 2004.

Gomes, R., A Internacionalização das Atividades Tecnológicas pelas Empresas Transnacionais: elementos de Organização Industrial da Economia da Inovação. Tese de Doutoramento, Instituto de Economia - IE/Unicamp, fevereiro de 2003.

Markusen, A., "Sticky Places in Slippery Sspaces: a typology of industrial districts", Economic Geography, 72, p.293-313, 1996.

Porto, D.; Cano, N.; Silva, A.L.G., Arranjo produtivo de Telecomunicações de Campinas/SP. Relatório Final, Contrato BNDES/FINEP/FUJB Arranjos e Sistemas Produtivos Locais e as Novas Políticas de Desenvolvimento Industrial e Tecnológico, NT 18, IE-UFRJ, 2000.

Queiroz, S.; Zanatta, M.; Andrade, C., "Internationalization of MNCs' technological activities: what role for Brazilian subsidiaries?", trabalho apresentado na SPRU Conference in honour of Keith Pavitt, Brighton, 13-15 nov., (www.sussex.uk/ Units/spru/events/KP_Conf_03/documents/Queiroz.pdf), 2003.

Rama, R.; Ferguson, D.; Melero, A., New economic agents and new form of concentration in the electronics industries of Madrid: Lessons for emergings regions, FINEP/British Council, Rio de Janeiro, 2002.

Simões, J., Regulamentação da Lei de Informática em fase final; governo diz que vai simplificar o acesso e incentivar mais P\&D do exterior, Inovação UNICAMP, http://www.inovacao.unicamp.br/report/news-leideinformatica.shtml, 2005.

Souza, M.C.A.F.; Garcia, R., O Arranjo Produtivo de Alta Tecnologia da Região de Campinas - Estado de São Paulo - Brasil, UNICAMP/IE/NEIT, Campinas, 1998.

Stefanuto, G. N., "O programa SOFTEX e a indústria de software no Brasil", Tese de Doutoramento, Instituto de Geociências, DPCT, UNICAMP, Campinas, 2004.

Suzigan, W.; Furtado, J.; Garcia, R.; Roselino Jr., J.E.S., Perspectivas de Reestruturação das Políticas de Financiamento do Desenvolvimento Tecnológico no Brasil, Relatório final, Convênio FINEP/FUNDAP, Campinas, 2001.

Trullén, J.; Lladós, J.; Boix, R., "Economía del Conocimiento, Ciudad y Competitividad", Investigaciones Regionales, outono, n.001, p.139-161, Alcalá de Henares, Espanha: Asociacíon Española de Ciencia Regional, 2002. 